\title{
REVIEW AND CITATION STYLE IN RESEARCH ARTICLE INTRODUCTIONS: A COMPARATIVE STUDY BETWEEN NATIONAL AND INTERNATIONAL ENGLISH-MEDIUM JOURNALS IN MEDICAL SCIENCES
}

\author{
Safnil Arsyad, Muhammad Zaim and Dian Susyla
}

\begin{abstract}
Reviewing and citing literature are essential elements determining the quality of academic texts such as research articles (RAs); however, it is not easy to review and cite literature especially when writing in a foreign language such as Indonesians writing in English. The purpose of this study is to investigate the review and citation style in English RA introductions published in medical science journals written by Indonesian and international authors. Forty English RA introductions were analysed on the review and citation style and linguistic features such as tenses and citation type. The results show that there are more similarities than differences in the review and citation style and linguistic features of RA introductions in the two different medical journals. However, Indonesian writers in medical sciences should include negative evaluation when reviewing and citing other's work in their English RA introductions to be successful if submitted to an international journal.
\end{abstract}

\section{Keywords}

research article introduction, review and citation style, communicative unit, introduction section

\section{Introduction}

Reviewing and citing relevant literature are absolutely essential in academic writing, such as in essays, theses, research reports, dissertations and research articles (cf. Dontcheva-Navratilova 2016, Hyland 1999, Kwan et al. 2012, Kwan 2009, Kamimura 2014, Soler-Monreal \& Gil-Salom 2011, Onwuegbuzie et al. 2012, Ridley 2012, Shooshtari et al. 2017, Arsyad \& Adila 2017). Academic texts always attempt to refer to relevant literature to demonstrate that their writing is connected with other works in the literature. The need to cite relevant literature in academic writing is also required because knowledge on all topics has been previously developed by others and the main purpose of an academic text is to extend readers' knowledge on a particular topic. It is almost impossible for an author to help extend readers' knowledge on a particular topic without discussing the available knowledge in the literature. 
Writing a literature review in a scientific essay is not easy, especially for students or new writers not only when writing in a second or foreign language but also in their first language. According to Kwan et al. (2012), the difficulty of writing a literature review is mainly due to the complexity of the writing processes, such as determining which opinion is appropriate to cite, how to address the opinion with our own words properly, how to combine the opinion of several authors into a sentence or how to criticize the previous writer's opinion correctly and appropriately. As suggested by Kwan et al., many questions need to be answered by an author in reviewing and citing literature because textbooks on literature review writing have not been able to fully answer the above questions, i.e. the guidelines are still ambiguous especially for students or novice writers.

To review and cite literature in an academic text is not just to rewrite or restate the important points found in relevant sources. According to Onwuegbuzie et al. (2010: 173, as cited in Onwuegbuzie et al. 2012: 2), a literature review is “ $\ldots$ an interpretation of a selection of published and/or unpublished documents available from various sources on a specific topic that optimally involves summarization, analysis, evaluation, and synthesis of the documents". Yet another definition of a literature review is proposed by Machi and McEvoy (2009: 4, as cited in Onwuegbuzie et al. 2012: 4): "A literature review is a written document that presents a logically argued case founded on a comprehensive understanding of the current state of knowledge about a topic of study. This case establishes a convincing thesis to answer the study's question". Thus, reviewing and citing references is the result of understanding, analysing, evaluating, summarizing and using the information found in available literature in order to situate, argue for or against and justify a particular claim in an academic text.

\subsection{The purposes of reviewing and citing references in RA introductions}

Authors have to convince readers that their RA is an important piece of academic writing to read, which can be done effectively by citing relevant literature in the introduction section of their RA. Authors are also expected to evaluate the related studies in the literature, especially on the methods or findings of previous relevant studies in order to find the rationale for the research. This is because a research project is carried out because there is a limitation, inconsistency or fault in previous studies so that there is a gap of knowledge or information to fill in by the new research (Swales 1990). Hence, the results of the research activities that will be or have been conducted are expected to provide information to fill in the gap or to increase readers' knowledge and that is the contribution of the research activity. Similarly, Belcher (2009: 140) suggests “... you must relate your research to the previous research in order to be published". 
According to Belcher, RAs can only be accepted for publication in a reputable international journal if the writers refer to the results or findings of previous relevant studies in order to show what has been investigated and what has not, which questions have been answered and which ones have not, which problems have successfully been solved and which ones have not. Thus, research results or findings are expected to extend readers' knowledge on that particular research topic in that particular discipline.

There are several objectives of reviewing and citing literature in an academic text, such as to respect other authors' work, to avoid plagiarism, to support an argument, to help promote colleagues' writing on the same or related topic, to convince readers that one has read plenty of readings on the topic and to show readers that one is a member of a particular discourse or discipline community (Swales \& Feak 2012). Thus, according to Swales and Feak, where an argument and persuasion are necessary, citation is usually used and therefore, it can be found in many places in an RA. However, based on recent research results on literature reviews, such as by Cronin (2005, as cited in Swales \& Feak 2012: 340 ), the main reason for reviewing literature is to show that the work cited carries important information or ideas relevant to the present work.

\subsection{The review and citation style of RA introduction}

The RA introduction section is the main place where authors evaluate or review what has been investigated or discovered by other researchers in previous related studies (Swales 1990). More specifically, according to Swales, RA authors need to provide an explanation and assessment on the findings of previous studies related to the present work to create a rationale for their research project. In addition, Swales (2004) suggests that reviewing literature is an essential element in the introduction section and therefore it can be found in several places in the introduction section.

After convincing readers that the research topic is important by supporting it with reference from previous studies, the authors have to indicate a gap of knowledge or information contained in previous relevant studies in order to create a logical reason or niche for the research project (Swales 1990). This rhetorical attempt is usually done by evaluating or criticizing the results or findings of previous research referred to (Swales 1984). Crookes (1986) and Hopkins and Dudley-Evans (1988) found that the cycle between reviewing literature and supporting the research project in the CaRS model occurs because after reviewing items of previous research the writer formulates an evaluative statement showing a gap in previous research findings. Kwan et al. (2012) also suggest that the evaluation of past research results is an important part of a 
literature review conducted by RA authors but evaluating others' work is often difficult for novice researchers or students, especially in determining what is to be evaluated and what criteria will be used in evaluating the opinion or findings of other researchers.

There are four possible communicative purposes or functions that may be used by RA authors in reviewing related research findings: 1) disagreeing in some respects with the previous research results; 2) considering the results of previous studies to be invalid and unreliable; 3) answering certain questions left from previous studies; and 4) finding the need to look further in the development of a particular case (Swales 1990). The specific feature of these rhetorical strategies, according to Swales, in addition to the rhetorical cycle, is the use of negation words and negative verbs while their main communicative purpose or function is to convince readers that previous studies have shortcomings or limitations and this reason is used in order to justify the present research project. In order to achieve this communicative goal, RA authors argue logically and convincingly so that readers accept that the previous related studies have some form of limitations or deficiencies. Swales found out that these rhetorical strategies are crucial especially in the context of highly competitive research environments where researchers face tough competition to obtain the chance to conduct research, and to succeed in such competition requires a strong and convincing argument. The author's ability to critically evaluate the existing literature as a basis for research activities in RAs will be a major consideration for the journal editor and reviewers in deciding whether or not the RA is acceptable for publication.

Swales (2004) adds an optional communicative purpose of reviewing and citing literature to his CaRS model of RA introductions, i.e. presenting positive justification in order to accommodate the communicative purpose of reviewing literature which is not aimed at evaluating the cited work. Positive justification is a citation that is not meant to criticize or evaluate other authors' opinions or results of previous studies but to accept and support the author's opinion or argument to justify the importance of a research project. Even though only an optional step, citation in the form of positive justification is often found primarily in relatively new research topics or in an academic culture in which criticizing the opinion or findings of other researchers is not yet culturally acceptable.

\subsection{Verb tense and style choices of review and citation in RA introductions}

The choice of a verb tense (i.e. the preferred form of verb based on the timing of an event or action) and aspect (i.e. the choice of sentence patterns indicating whether or not an activity or event has been completed) is one of the most important linguistic features of literature reviews in academic writing. There are 
three tenses commonly used in citation: past tenses used when referring to a single study, present perfect tense used when referring to an area of inquiry, and present tense used when referring to generally accepted knowledge of the field (Feak \& Swales 2009). However, according to Feak and Swales the difference between the three types of forms (tense and aspect) above is not obvious; authors may opt for using different forms for a specific purpose. The change from past to present perfect and then to present tense by RA authors suggests that the cited ideas or research findings are closer to the author's research in various forms, such as closer to the author's opinion itself, closer to the topic or the author's own research findings, or closer to the theory or knowledge that is generally accepted (in the acceptable current state of knowledge).

A study on this topic was conducted by Chen (2009), who analysed 100 Ph.D. dissertations written in English in multiple disciplines (i.e. Linguistic, Sociology, Economics, Marketing, Philosophy, Physics, Chemistry, Computer, Biology and Engineering) on the author's choice of verb tenses (i.e. present tense, past tense, perfect tense and other tenses). Chen found that the use of present tense is the most dominant one while past tense is the second most dominant one in all disciplines. According to Chen, past tense is used when citing new research results; however, when that particular research finding has become 'a tenet of science', then present tense is used (2009: 144). Thus, because authors usually prefer citing already widely accepted information or theory in an academic text rather than a new research finding, present tense is more often used especially when authors cite sources. Feak and Swales (2009) suggest that the choice of verb also determines the choice of tense in citation. According to Swales and Feak, the verbs argue, suggest, claim, or maintain tend to be used for present tense; the verbs find, identify and reveal tend to be used in past tense.

The type of citation (integral or non-integral) has also become a focus of discourse studies on the RA genre. According to Feak and Swales (2009), in integral citations the authors of the cited research article become the subject of the clause or sentence of the citation and placed at the beginning of the clause or sentence while in a non-integral citation the cited authors are usually placed at the end of the citation in paretheses. In addition, Feak and Swales suggest that in the integral citation the author of the cited work is considered more important and therefore it is mentioned at the beginning of the citation sentence, while in the non-integral citation, the information obtained from the reference is considered more important.

In his study, Hyland (1999) found that non-integral citation was more frequently used in biology, physics and electric engineering RAs, while integral citation was more frequently used in philosophy RAs. Similarly, Yeh (2010) 
found that non-integral citation was used frequently in English RAs in the discipline of TESL (Teaching English as a Second Language). This is because "content counts for more than connections" (Cronin 2005, as cited in Swales and Feak 2012: 340), i.e. the main objective of citing others' works is to present all information from studies or literature relevant to the present work in order to justify the importance of their research topic and project.

\subsection{Studies on review and citation style in Indonesian RA introductions}

At least two rhetorical studies on review and citation style in Indonesian RA introductions have been conducted by Indonesian genre analysts. Arsyad (2003) found that citations in Indonesian RAs are found in the entire introduction section of the RAs, even from the very beginning of the section. These citations, according to Arsyad, were used for several different communicative purposes. First, they were used to inform readers' background information or knowledge, such as definition of key terms, a description of the history of research topics, and government policy. This was done to introduce the field of research in order to put it into context of the specific research topic. The second purpose of citation is to support the importance of the research topic by demonstrating that the problem raised in the study actually exists; this was done by using facts and statistics quoted from literature sources. The last purpose of citation in the Indonesian RAs was to implicitly show readers that the authors are already familiar with the research topic; that was done by referring to the writings of others that are relevant to the topic of the study. By so doing, the authors told readers that they follow the latest developments on the topic of their research. In some Indonesian RA introductions, the literature review and citation is titled as Review of Literature, Overview Assessment Theory or Theory.

A study by Adnan (2009) revealed that negative evaluation or critique on previous relevant studies in order to create a research space as a feature commonly found in English RA introductions is not found in Indonesian RA introductions. According to Adnan, this was because the Indonesian RA writers may find it unnecessary to do so in order to convince readers that their research project is important because there is a culturally more acceptable way to do so. They only need to indicate the existence of a problem related to an important topic which needs to be investigated or solved. Another possible reason was because the Indonesian writers do not need to compete hard in order to publish an article in an Indonesian research journal. In other words, the style of literature review found in the Indonesian RA introduction is not affected by the language of the article but by the context of the research and the journal article writing in Indonesia. 
The studies by Arsyad (2003) and Adnan (2009) are descriptive studies on Indonesian RA introductions written by Indonesian speakers in one or several disciplines. These studies are important in order to know how Indonesian authors review and cite relevant literature in their Indonesian RA introductions; however, these studies do not provide necessary information on how Indonesian authors review and cite references when writing RAs in English. According to Connor et al. (2008), a more suitable approach for this kind of research is a comparative approach. Connor, et al. suggest that although rhetorical comparative studies have been heavily criticized, this research approach is still very important because the use of English as a foreign language in an academic context has increased globally; therefore, the results of these studies are useful for foreign language teaching and learning success. This is the rationale for this study, i.e. to find out the similarities and differences between the review and citation style in English RA introductions in medical science published in an Indonesian journal and an international journal. In particular, this study is aimed at investigating the review and citation style in English RA introductions by Indonesian academics published in the Acta Medica Indonesiana (AMI) and the ones by international authors published in the British Medical Journal (BMJ). The main questions addressed in this study are the following:

a) Are there any surface feature differences between AMI and BMJ RA introductions?

b) Are there any differences in review and citation strategies between AMI and BMJ RA introductions?

c) Are there any differences in tense and aspect of review and citation between AMI and BMJ RA introductions?

d) Are there any differences in citation types between AMI and BMJ RA introductions?

The answers to the above questions are expected to show how non-native speakers of English (i.e. the Indonesian speakers) in medical science review and cite literature when writing RAs in English published in an Indonesian national journal.

\section{The study}

\subsection{The corpus}

For this study, forty English RA introductions were chosen from two research journals in the field of medical science. The distribution of the research articles 
in the corpus in this study is shown in Table 2 below while the list of the articles included in the corpus of this study is given in the Appendix.

\begin{tabular}{clccc}
\hline No. & Journal & Code & $\begin{array}{c}\text { Number of RA } \\
\text { introductions }\end{array}$ & Percentage \\
\hline 1. & British Medical Journal & BMJ & 20 & $50 \%$ \\
\hline 2. & Acta Medica Indonesiana & AMI & 20 & $50 \%$ \\
Total & & & 40 & $100 \%$ \\
\hline
\end{tabular}

Table 1: The distribution of research articles in the corpus of this study

The articles from both journals forming the corpus of this study were taken from the latest issues in order to represent the most recent features of the research articles published in the journals. The reasons for choosing these two journals are as follows: 1) both journals publish research articles in medical science; 2) both journals publish articles in English; 3) both journals are indexed by an international indexing organization (Scopus) although they have a very different impact factor values [i.e. BMJ: 17.15 and AMI: 0.17 (SJR SCImago 2004-2014)]; and 4) for a practical reason as both journals are open-access online journals providing free downloaded copies of published articles. The differences between these two journals are that the articles published in AMI journal were mostly written, reviewed and edited by Indonesian speakers who use English as a foreign language or non-native speakers of English while the articles published in BMJ were written by international writers; some of them are native speakers of English but all articles were edited and proof-read by English native speakers. However, as indicated in the title, this study was not aimed at comparing styles or strategies and linguistic realization of review and citation in RA introductions written by native and non-native speakers of English but between those published in a national and an international journal in medical science.

\subsection{Identifying the communicative units in the literature review}

The communicative unit in the literature review of the RA introduction is called a strategy in this study following Kwan et al. (2012). Several steps were followed in order to identify and code the strategies used by RA authors in arguing and convincing readers that their research topic and project is important and necessary. First, the possible three communicative units or moves (1. establishing a territory, 2. making topic generalization, and 3. occupying the niche) in the RA introduction following Swales' CaRS model (2004: 141) were 
identified by looking at the communicative purpose of every clause or sentence in the text. Second, the analysis focused only on two communicative units (establishing a territory and making topic generalization) because these two units are argumentative while the third unit (occupying the niche) is usually descriptive in nature and therefore very rarely addressed and justified by using reference to the literature. Also, the analysis took in consideration the clauses or sentences in which the authors cite references to support the importance of their research topic and project; identifying the strategy was also done by looking at specific lexical items or phrases and discourse markers used in the text. Fourth, every strategy was coded mainly by referring to the steps of Move-1 and Move-2 of Swales' CaRS model (Swales 1990); however, a modification on the CaRS model was made to accommodate more strategies found in the texts. Thus, the possible strategies in Move-1 were Strategy-1 (stating a general claim), Strategy-2 (defining a key term), Strategy-3 (stating the research problem), Strategy-4 (introducing and justifying the research topic) and Strategy-5 (suggesting a solution). In addition, a modification was also made on Move- 2 of the CaRS model by introducing Strategy-6 (negatively evaluating the methods or results of previous studies), Strategy-7 (indicating a gap from previous studies), Strategy-8 (question-raising from the results of previous studies) and Strategy-9 (adding to what is already known in the literature) and by adding one more possible strategy: Strategy-10 (reviewing items of previous relevant studies). Thus, in this study there are ten possible strategies in the literature review and citation of the RA introduction. Finally, since identifying and coding the communicative units or strategies in the RA introductions involved subjective judgement, an independent rater was involved in the process of communicative unit analysis in order to validate the analysis results. The review and citation style found in the RA introductions in the two different journals (BMJ and AMI) were compared in order to look at the similarities and differences between these two different journals.

Other features of review and citation style in the RA introductions such as the choice of tense, the choice of citation type, the length of the RA introduction, the number of authors per article and the number of references cited in the RAs were also analysed following Feak and Swales (2009). The analysis of tense and aspect was done by identifying the main clauses in which the authors cite the literature; since almost all citation acknowledgement in the RA introductions from the two different journals was done by using a footnote format, the clause type analysis was performed only on the ones with a footnote marker. The linguistic features found in the RA introductions in the two different journals were compared in order to see the similarities and differences between these two different journals. 
An independent rater involved in this study was a lecturer at the English department of Teacher training and education faculty who has an MA degree in Linguistics. First, the independent rater was trained on how to identify the possible moves and strategies and the linguistic features in the texts with examples following the analysis procedure as described above. Then, she was given two weeks to carry out the strategy identification analysis of ten out of 40 RA introductions (25\%) from the corpus of this study. Inter-rater correlation agreement was then calculated and the results showed 80 per cent agreement or an excellent inter-rater agreement (Orwin 1994, as cited in Kanoksilapatham 2005). Some differences only occurred in coding the possible communicative units or strategies found in the RA introductions while almost no difference occurred in coding the other aspects of the RA introductions in both journals (BMJ and AMI). After a few discussions between the researcher and the co-rater, full agreement was finally achieved.

\section{Results and discussion}

\subsection{The surface features of the RA introductions in the corpus of the study}

Before the analysis was performed, the two sets of RA introductions in the corpus of the study were compared on their surface features, i.e. the average number of references, the number of authors involved in writing each article and the average number of words per article. The results are presented in Table 2 below.

\begin{tabular}{cccc}
\hline No. & Surface features & BMJ & AMI \\
\hline 1. & Average number of reference in the RA introduction sections & 14.1 & 10.2 \\
\hline 2. & Average number of authors involved in writing the article & 6.6 & 4.2 \\
3. & Average number of words in the RA introduction sections & 450 & 340 \\
\hline
\end{tabular}

Table 2: The surface features of the RA introductions

As can be seen in Table 2, RA introductions in the BMJ outscore the RA introductions in the AMI on all aspects although the differences are not significant except for the average number of words per RA introduction in which the BMJ is significantly higher than the AMI. This shows among other things that compared to the authors of AMI RAs, the BMJ RA authors need to argue more for the importance of their research topic and research project in order to convince readers to read their articles. 
This finding contradicts the one of previous studies, e.g. Arsyad (2003), in which he found that Indonesian authors tend to write a longer RA introduction when writing in Indonesian because they address more rhetorical issues in the introduction, such as definitions of important or key terms, the history of research field, government policy related to the research topic, the problem of the research and so on. This implies that Indonesian RA authors in medical journals used a more direct rhetorical style when writing in English compared to those in social sciences and humanities as found by Arsyad (2001). The average number of RA authors per article in the corpus of this study as seen in the above table reflects the current practice in which team authors are much more dominant than solo authors in all disciplines (Wuchty et al. 2007, as cited in Swales \& Feak 2012: 250-257). According to Wuchty et al., unlike in the past, nowadays high quality research findings and research papers are produced by teams rather individuals. This is probably because of the advantages of working in groups rather than working alone in conducting academic work such as doing research and writing a research paper. Belcher (2009) also suggests that writing academic texts for publication should not be an individual and closed activity but a social and open one, as writing in a group is more fruitful than writing alone.

\subsection{The rhetorical function of citation in RA introductions}

Next the analysis focused on the strategies used by the RA writers in reviewing and citing literature in the RA introductions. As mentioned earlier, this analysis was focused only on the clauses in which the authors cite a reference or infer from previous research results or findings. The analysis results are presented in Table 3 below. 
Review and Citation Style in Research Article Introductions: A Comparative Study between National snd International English-Medium Journals in Medical Sciences

\begin{tabular}{clcc}
\hline Strategy & Review and Citation Communicative Functions or Strategies & $\begin{array}{c}\text { BMJ } \\
\text { (f) }\end{array}$ & $\begin{array}{c}\text { AMI } \\
\text { (f) }\end{array}$ \\
\hline 1. & Stating a general claim & 4 & 10 \\
\hline 2. & Defining a key term & 2 & 5 \\
\hline 3. & Stating the research problem & 1 & 1 \\
\hline 4. & Introducing and justifying the research topic & 19 & 18 \\
\hline 5. & Suggesting a solution & 6 & 6 \\
\hline 6. & Negatively evaluating the methods or results of previous studies & 7 & - \\
\hline 7. & Indicating a gap from previous studies & 17 & 17 \\
\hline 8. & Question-raising from the results of previous studies & 1 & 1 \\
\hline 9. & Adding to what is already known in the literature & 1 & 2 \\
\hline 10. & Reviewing items of previous relevant studies & 20 & 20 \\
\hline
\end{tabular}

Table 3: Strategies in review and citation of the RA Introductions

As can be seen in Table 3, there are ten possible review and citation functions or strategies used in the RA introductions identified in the corpus of this study. The first significant difference between the two sets of RA introductions is in the occurrence of Strategy-1 (stating a general claim or S-1) with it being found much more frequently in the AMI RAs than in BMJ RAs. A general claim is a statement by the RA author usually at the beginning of the RA introduction and it is not the topic of the RA. Below are examples of S-1.

(1) Physical activity has well documented health benefits. ${ }^{I}$ Population level cohort studies have shown that people who exercise enjoy a higher quality of life and improved health status compared with those with sedentary behaviours, with subsequent reductions in their risk of adverse outcomes such as admissions to hospital. (BMJ-13)

The increasing incidence of antibiotics resistance is getting more global attention. The absence of antibiotic regulation in most Asian countries, including Indonesia, is believed to have contribution to the rapidly increasing infections of multiresistance pathogenic bacterias. ${ }^{l}$ (AMI-2)

The title of BMJ-13 as in Example 1 is Comparative effectiveness of exercise and drug interventions on mortality outcomes: meta-epidemiological study while 
the title of AMI-2 is Phenotype Characterization of Beta-Lactamase Producing Entero-bacteriacea in the Intensive Care Unit (ICU) of Cipto Mangunkusumo Hospital in 2011. It can be seen that the first and second clauses of the first paragraph in these two RAs are not the topic of the RAs. A general claim, as in the CaRS model, is a statement about knowledge, practice or phenomena which functions to present research field and problem background (Swales 1990: 146). This typical communicative unit was also found by Kwan $(2006,2012)$ when he analysed literature reviews and citations of doctoral theses in the field of applied linguistics and RA introductions in the fields of computer science and information systems. According to Kwan, in this strategy the authors address claims about the state of knowledge of theories related to the field of research reported in the thesis or RA. The general claim at the beginning of the RA introduction also has the function of preparing readers who are new to the research field so that they can easily comprehend the text. The different frequency of S-1 in the two sets of RAs shows that more AMI RA authors think that they need to provide necessary background knowledge or schemata for their potential readers.

The second difference between the two sets of RA introductions is the occurrence of Strategy-2 (defining a key term) which is found far more frequently in the AMI RAs than in the BMJ RAs. Key terms are important words usually appearing in the title of the RAs; as in S-1 this communicative unit also functions to activate readers' schemata in order to enable them to successfully understand the text. Below are examples of S-2.

Chronic kidney disease, most commonly defined by a reduced glomeruler fitration rate (GFR) or abnormal concentrations of proteinuria, or both, is an important public health problem, ... ${ }^{1-3}$ (BMJ-12)

Lipopolysaccharide-binding protein $(L B P)$ is a new marker useful as an infection marker to measure the severity of the infection and to evaluate the result of treatments, while Procalcitonin has been established as an infection marker due to its level increases in bacterial infections. ${ }^{7.8}$ (AMI-7)

As in the above examples, Strategy-2 (S-2) is also addressed at the beginning of the RA introductions (clause- 1 and clause- 4 of the first paragraph). The title of BMJ-12 is Blood pressure lowering and major cardiovascular events in people with and without chronic kidney disease: meta-analysis of randomised controlled trials and the title of AMI-7 is Role of Combined Procalcitonin and Lipopolysaccharide-binding Protein as Prognostic Markers of Mortality in Patients with Ventilator-associated Pneumonia. In Kwan's study, this 
communicative unit is also found but included in Strategy-1A or "surveying the existing state of knowledge and non-research practice" (Kwan 2006: 40). In Indonesian RAs published in Indonesia, definitions of important or key terms is a common rhetorical step since the majority of the research journals are multidiscipline journals in which the readers may come from different disciplines (Arsyad 2001). The use of definitions of key terms in AMI RA introductions may reflect a common practice in Indonesian RA introductions since all authors of AMI RAs are Indonesian writers.

The last significant difference between the two medical journals as shown in Table 3 is in the occurrence of Strategy- 6 (negatively evaluating the methods or results of previous studies) with it only being found in BMJ RA introductions. In Swales (2004) the communicative unit of critiquing or 'counter-claiming' is included in the 'indicating a gap' move but not in this study because they are considered two different rhetorical moves. The following are examples of Strategy-6 in the RA introductions in the corpus of this study:

$$
\begin{aligned}
& \text { These studies, however, were mostly short term trials that included a limited } \\
& \text { number of selected number of selected patients with close follow-up. }{ }^{9,1} \text {. Safety } \\
& \text { data from clinical practice are lacking. }{ }^{13,14} \text { (BMJ-5) } \\
& \text { Some studies did report the beneficial effects of expectations, but these studies } \\
& \text { were small and had methodological flaws. }{ }^{11} \text { (BMJ-11) }
\end{aligned}
$$

Both examples above are from BMJ RA introductions because Strategy- 6 is not found in AMI RA introductions. This finding confirms those by Mirahayuni (2002), Adnan (2009), Basthomi (2009) and Arsyad (2013), who also found that Indonesian RA authors, although writing in English, are reluctant to criticize or point at the weaknesses or flaws of findings or methodology of previous studies. According to Arsyad, the Indonesian RA authors prefer evaluating others' works by indicating a gap (Strategy-7) because it does not require them to challenge other people's work. Thus, the differences show that Indonesian authors (the AMI RA authors) although writing RAs in English still follow some common rhetorical features of Indonesian RAs published in Indonesian and for Indonesian readers.

The reluctance to criticize other people's work in academic texts such as RAs is not only found in the Indonesian academic context. Zhang and $\mathrm{Hu}$ (2010) also found that Chinese RA authors in the discipline of medical science tend to avoid pointing at the weaknesses or errors in other people's work in order to refrain from conflict and to promote social harmony. According to Zhang and 
$\mathrm{Hu}$ (ibid.), the nonexistence of negative evaluation rhetorical steps in academic texts written by Chinese scholars, such as claiming that other people's work is erroneous or has some kind of flaws, is related to the culture of Chinese people who have different academic logical and self-publication styles in their academic texts from the ones in English or international academic culture. In other words, Zhang and Hu claim that the rhetorical style of academic texts, such as RAs by Chinese authors is influenced by Chinese culture particularly in the way they perceive other people and other people's work in academic communication using an international language.

The possible reason for the reluctance of Indonesian authors to criticize other people's work is the loose publication competition among authors in Indonesia. Unlike in high impact journals, it is not yet hard to win a publication opportunity in an Indonesian international journal, such as in the AMI journal. According to Swales (1990: 142), the rhetorical attempt and style in order to justify a particular research topic and project depends on "...the existing ecological competition, on the size and importance of the niche to be established, and on various other factors such as the writer's reputation". However, Indonesian authors' reviews and citation style in English RA introductions may change if Indonesian journals are more exposed to outside world and international authors will be attracted to publish their RAs in the journals resulting in a tighter competition to publish in the journal.

Besides the differences described above, the two sets of RA introductions also display similarities, such as on the occurrence of strategies of introducing and justifying the research topic, indicating a gap from previous studies and reviewing items of previous relevant studies. As can be seen in Table 3, almost all BMJ and AMI RAs have these communicative units implying that these three strategies are important in RA introductions in medical sciences. Thus, for the authors in both groups of RAs, a research topic must be explicitly introduced and justified, the research project must be introduced and justified and items from previous relevant studies must be reviewed. Another similarity between these two sets of RA introductions is the use of citations in several places in the text and for several different purposes, such as to support the importance of the research topic and the importance of the research project. Hence, the introductions of AMI RAs are more similar to the ones suggested by Swales (1990 and 2004) in terms of review and citation strategies. A similar conclusion is also drawn by Mirahayuni (2002) and Adnan (2009) when they suggest that the English RAs in applied linguistics and medical science written by Indonesian speakers are rhetorically more similar to the ones by English native speakers than to those written in Indonesian. This implies that the Indonesian writers have 
attempted to adjust the review and citation style of their RAs when writing in English although they are not yet fully successful.

\subsection{Tense and aspect of review and citation in RA introductions}

Another part of the analysis focused on the tense and aspect of the clauses or sentences of the citations found in the introduction section of the RAs. The results are presented in Table 4 below.

\begin{tabular}{clcc}
\hline No. & Tense \& Aspect & BMJ (\%) & AMI (\%) \\
\hline 1. & Present tense & $125(61.3 \%)$ & $124(78 \%)$ \\
2. & Past tense & $33(16.2 \%)$ & $17(10.7 \%)$ \\
3. & Present perfect tense & $46(22.5 \%)$ & $18(11.3 \%)$ \\
Total & & $204(100 \%)$ & $159(100 \%)$ \\
\hline
\end{tabular}

Table 4: Tense and aspect of review and citations

As can be seen in Table 4, the majority of the clauses or sentences in the literature review sub-section of the RA introduction are in present tense in both journals while the frequency and percentage of past tense and present perfect tense are almost similar in both journals. Below are examples of different tense and aspect in the corpus of the study.

(4) This happens not only because of the resistance of Gram negative bacteria is faster than those of Gram positive, but also the discovery and development of new antibiotics to fight Gram negative bacteria are far fewer. ${ }^{2}$ (AMI-2)

Kim et al. (2001) ${ }^{14}$ examined the roles of caspase-3 and CAD activation in relation to the apoptotic death of germ cells. (AMI-4)

Human development rates are highest during the first trimester of pregnancy. ${ }^{2}$ (BMJ-1)

Use of prescription opioids by elderly people in the United States has grown considerably, ${ }^{1-4} \ldots$ (BMJ-2)

According to Feak and Swales (2009) and Swales and Feak (2012) present tense in citation is used when the writers cite commonly accepted knowledge in the research field while past tense is used when they refer to a particular research 
activity, and present perfect tense is used when they refer to nonspecific studies already conducted in the past. Also, Swales (1990) suggests that reference to a previous study without mentioning the author's name tends to be expressed in present tense. As can be seen in Table 4, a significant difference between the two groups of the RAs is only in the percentage of present perfect tense with it being used in BMJ RA introductions almost twice more frequently than in AMI RA introductions. This implies that compared to AMI RA authors, more BMJ RA authors refer to nonspecific studies found in the literature in their RA introduction. This finding also confirms the ones from previous studies on the use of tense in scientific writing such as research articles in which, according to Gledhill (2009), the introduction and discussion sections are characterized as using present tense while the method and results section are featured by the use of past tense.

\subsection{Citation types in RA introductions}

The next step of the analysis carried out in this study was on the type of citation found in the RA introductions in the corpus of this study. The analysis results are shown in Table 5 below.

\begin{tabular}{clcc}
\hline No. & Type of citation & BMJ (\%) & AMI (\%) \\
\hline 1. & Integral & $0(0 \%)$ & $6(3.8 \%)$ \\
\hline 2. & Non-integral & $204(100 \%)$ & $153(96.2 \%)$ \\
\hline Total & & $204(100 \%)$ & $159(100 \%)$ \\
\hline
\end{tabular}

Table 5: Citation type in the RA Introductions

Table 5 shows that all (100\%) citations in BMJ and almost all (96.2\%) in AMI use the non-integral type. Thus, there is no significant difference between these two sets of RA introductions in terms of the type of citation used in the text. Below are examples of integral and non-integral citation type found in the corpus used in this study.

(5) Kim et al. (2001) ${ }^{14}$ examined the roles of caspase-3 and CAD activation in relation to the apoptotic death of germ cells. (AMI-4)

Along with the increasing frequency of surgery, perioperative infection has been one of the most important problems needed to be resolved. ${ }^{\text {(AMI-14) }}$

Blood pressure is an important determinant of the risk of cardiovascular disease in the general population. ${ }^{8}(\mathrm{BMJ}-12)$ 
The integral type of citation is used when the authors consider that the author cited is more important than the information contained in the article while the non-integral citation is used when the authors consider that the information contained in the cited reference is more important than the authors of the reference (Hyland 1999, Swales \& Feak 2012). This finding confirms the ones by Hyland (1999) and Yeh (2010), who also found that the use of non-integral and non-subject citation was much more dominant than the use of integral citation in the majority of his RA samples except in the discipline of philosophy. According to Swales and Feak (2012), the reason for using this type of citation is because the main objective of citing reference is to present to readers others researchers' studies already conducted or works published previously and relevant to the present research topic rather than "showing respect for previous authors or acknowledging intellectual property rights of earlier authors" (2012: 340).

Another possible cause for the dominance of non-integral citation in the data of this study is the use of the 'footnote' or 'endnote' acknowledgement format implemented in both journals. Using this format, the authors are encouraged to present the source of the cited reference outside the text such as at the footer of the page or at the end of the article in order not to destruct the flow of information presented in the text. In the instruction for authors of AMI journals, for example, it is clearly stated that authors have to order their references using numbers in which the numbers appear in superscript as in the way of 'footnote' or 'endnote' acknowledgement format. Thus, writing the source of information cited in a text at the footer or at the end of the text the citation format is classified as 'non-integral (research prominent)' as in the example given by Feak and Swales (2009: 46).

\section{Conclusion}

From the results it can be concluded that there are more similarities than differences between the review and citation style and linguistic features of BMJ RA introductions and of AMI RA introductions. The differences are in the length of the RA introductions in terms of the number of words, the average number of reference per article, the average number of authors involved in writing each article and on several strategies used in the literature review and citation (i.e. Strategy-1, S-2, and S-6) while the similarities are in other strategies in the review and citation style (i.e. Strategy-3, S-4, S-5, S-7, S-8, S-9 and S-10), the use of tense and aspect of the citation (i.e. present tense, past tense and present perfect tense) and the use of citation type (integral and non-integral) in the literature review and citation of the RA introductions. This implies that, although writing in English, Indonesian authors in medical sciences are already familiar with the 
review and style and linguistic realization of citation in RA introduction sections in international journals in the same discipline. However, when writing for an international journal the Indonesian authors in medical sciences must fully utilize the review and citation style and linguistic features in their RA introductions as they are expected by international readers. This can be done by negatively evaluating the methods and/or results of previous studies in order to create a rationale for their research.

\section{Acknowledgements}

We would like to thank Dr. Zifirdaus Adnan from University of New England Australia, Dr. Dawn Bikowski from Ohio University USA and two anonymous reviewers for valuable feedback on earlier versions of this article.

\section{References}

Adnan, Z. (2009) 'Some potential problems for research articles written by Indonesian academics when submitted to international English language journals.' The Asian EFL Journal Quarterly 11(1), 107-125.

Arsyad, S. (2013) 'A genre-based analysis on the introductions of research articles written by Indonesian academics.' TEFLIN Journal 24(2), 180-200.

Arsyad, S. (2003) 'The rhetorical style of Indonesian research article introductions: A genre base analysis.' The Asian-Pacific Education Researcher 12(1), 27-62.

Arsyad, S. (2001) Genre Structure Analyses of the Indonesian Research Articles. Unpublished Ph.D. Dissertation. Canberra: Australian National University.

Arsyad, S. and Adila, D. (2017) 'Using local style when writing in English: The citing behaviour of Indonesian authors in English research article introductions.' Asian Englishes 20(2), 170-185.

Basthomi, Y. (2009) 'Examining research spaces in doctoral prospectus.' TEFLIN Journal 20(2), 140-158.

Belcher, W. L. (2009) Writing Your Journal Article in Twelve Weeks: A Guide to Academic Publishing Success. California: SAGE Publications.

Connor, U., Nagelhout E. and Rozycki W. V. (2008) 'Introduction.' In: Connor, U., Nagelhout, E. and Rozycki, W. V. (eds) Contrastive Rhetoric: Reaching to Intercultural Rhetoric. Amsterdam: John Benjamins Publishing Company. 1-8.

Chen, M. (2009) 'Tense of reporting in dissertation literature reviews.' Journal of Cambridge Studies 4(2), 139-150.

Cronin, B. (2005) 'A hundred million acts of whimsy?' Current Science 89, 1505-1509.

Crookes, G. (1986) 'Towards a validated analysis of a scientific text structure.' Applied Linguistics 7(1), 57-70.

Dontcheva-Navratilova, O. (2016) 'Rhetorical functions of citations in linguistics research articles: A contrastive English (English-Czech) study.' Discourse and Interaction 9(2), 51-74.

Feak, C. B. and Swales J. M. (2009) Telling a Research Story: Writing a Literature Review. Michigan: The University of Michigan Press. 
Gledhill, C. (2009) 'Colligation and the cohesive function of present and past tense in the scientific research article.' In: Banks, D. (ed.) Les Temps et les Textes de spécialité. Paris: L'Hramttan. 65-84.

Hopkins, A. and Dudley-Evans, T. (1988) 'A genre based investigation of the discussion sections in articles and dissertation.' English for Specific Purposes 7(2), 113-122.

Hyland, K. (1999) 'Academic attribution: Citation and the construction of disciplinary knowledge.' Applied Linguistics 20(3), 341-367.

Kamimura, T. (2014) 'Citation behaviors observed in Japanese EFL students'argumentative writing.' Journal of Pan-Pacific Association of Applied Linguistics 18(1), 85-101.

Kanoksilapatham, B. (2005) 'Rhetorical structure of biochemistry research articles.' English for Specific Purposes 24, 269-292.

Kwan, B. S. C., Chan H. and Lam C. (2012) 'Evaluating prior scholarship in literature reviews of research articles: A comparative study of practices in two research paradigms.' English for Specific Purposes 31(3), 188-201.

Kwan, B. S. C. (2009) 'Reading in preparation for writing a Ph.D. dissertation: Case studies of experiences.' Journal of English for Academic Purposes 3(3), 180-191.

Kwan, B. S. C. (2006) 'The semantic structure of literature review in doctoral theses of applied linguistics.' English for Specific Purposes 25(1), 30-55.

Machi, L. A. and McEvoy, B. T. (2009) The Literature Review: Six Steps to Success. Thousand Oaks, CA: Corwin.

Mirahayuni, N. K. (2002) Investigating Textual Structure in Native and Non-native English Research Articles: Strategy Differences between Indonesian and English Writers. PhD thesis. University of New South Wales of Sydney, Australia.

Onwuegbuzie, A. J., Collins, K. M. T., Leech, N. L., Dellinger, A. B. and Jiao, Q. G. (2010) 'A meta-framework for conducting mixed research syntheses for stress andcoping researchers and beyond'. In: Collins, K. M. T., Onwuegbuzie, A. J. and Jiao, Q. G. (eds) Toward a Broader Understanding of Stress and Coping. Mixed Methods Approaches. Charlotte, NC: Information Age. 169-211.

Onwuegbuzie, A. J., Leech, N. L. and Collins, K. M. T. (2012) 'Qualitative analysis techniques for the review of the literature.' The Qualitative Report 17(56), 1-28.

Orwin, R. G. (1994) 'Evaluating coding decisions.' In: Cooper, H. and Hedges, L. (eds) The Handbook of Research Synthesis. New York: Russell Sage Foundation. 139-162.

Ridley, D. (2012) The Literature Review: A Step-by-Step Guide for Students. Los Angeles: SAGE Publications.

SJR-SCImago. 2004-2012. 'Journal \& Country Rank.' Online document. 09 November 2016, from http://www.scimagojr.com) SJR-SCImago Journal \& Country Rank.

Soler-Monreal, C. and Gil-Salom, L. (2011) 'A cross-language study on citation practice in Ph.D. theses.' International Journal of English Studies 11(2), 53-75.

Shooshtari, Z. G., Jalilifar A. and Shahri, S. (2017) 'Ethnolinguistic influence on citation in English and Persian hard and soft science research articles.' $3 L$ : The Southeast Asian Journal of English Language Studies 23(2), 58-74.

Swales, J. M. (2004) Research Genres: Explorations and Applications. Cambridge: Cambridge University Press.

Swales, J. M. (1990) Genre Analysis: English in Academic and Research Settings. Cambridge: Cambridge University Press.

Swales, J. M. (1984) 'Research into the structure of Introductions to journal articles and its application to the teaching of academic writing.' In: Williams, R., Swales, J. and Kirkman, J. (eds) Common Ground: Shared Interests in ESP and Communication. Oxford: Pergamon Press. 77-86. 
Swales, J. M. and Feak, C. B. (2012) Academic Writing for Graduate Students: Essential Tasks and Skills. Michigan: University of Michigan Press.

Wuchty, S., Jones, B. F and Uzzi, B. (2007) 'The increasing dominance of teams in production of knowledge.' Science 316(5827), 1036-1038.

Yeh, C. (2010) 'Citation practices in TESL research articles: A comparative study.' Asian ESP Journal 6(2), 40-62.

Zhang, Y. and Hu, J. (2010) 'A genre-based study of medical research article introductions: A contrastive analysis between Chinese and English.' The Asian ESP Journal 6(1), 72-94.

\section{Appendix: Sources}

British Medical Journal (BMJ)

First trimester fatal growth restriction and cardiovascular risk factors in school age children: population based cohort study (BMJ 2014; 348:g14 doi:10.1136/bmj.g14)

Opioid prescribing by multiple providers in Medicare: retrospective observational study of insurance claims (BMJ 2014;348:g1393 doi:10.1136/bmj.g1393)

Change in mental health after smoking cessation: systematic review and meta-analysis (BMJ 2014;348:g 1151 doi:10.1136/bmj.g1151)

Explaining trends in Scottish coronary heart disease mortality between 2000 and 2010 using IMPACTSEC model: retrospective analysis using routine data (BMJ 2014; 348:g1088 doi:10.1136/bmj.g1088)

Safety of benzodiazepines and opioids in very severe respiratory disease: national prospective study (BMJ 2014; 348:g445 doi:10.1136/bmj.g445)

The impact of a bodyweight and physical activity intervention (BeWEL) initiated through a national colorectal cancer screening programme: randomised controlled trial (BMJ 2014;348:g1823 doi:10.1136/bmj.g1823)

Comparative effectiveness of radical prostatectomy and radiotherapy in prostate cancer: observational study of mortality outcomes (BMJ 2014; 348:g1502 doi: 10.1136/ bmj. g1502)

Delayed antibiotic prescribing strategies for respiratory tract infections in primary care: pragmatic, factorial, randomised controlled trial (BMJ 2014;348:g1606 doi:10.1136/ bmj. G1600)

Effectiveness of quadrivalent human papillomavirus vaccine for the prevention of cervical abnormalities: case-control study nested within a population based screening programme in Australia (BMJ 2014; 348: g1458 doi:10.1136/bmj.g 1458)

Long term duration of protective effect for HPV negative women: follow-up of primary HPV screening randomised controlled trial (BMJ 2014; 348:g130 doi: 10.1136/bmj. G130)

Efficacy of anti-inflammatory or antibiotic treatment in patients with non-complicated acute bronchitis and discoloured sputum: randomised placebo controlled trial (BMJ 2013; 347: 15762 doi: 10.1136/bmj. 15762)

Blood pressure lowering and major cardiovascular events in people with and without chronic kidney disease: meta-analysis of randomised controlled trials (BMJ 2013; 347: 15680 doi: 10.1136/bmj. 15680)

Comparative effectiveness of exercise and drug interventions on mortality outcomes: metaepidemiological study (BMJ 2013; 347: 15577 doi: 10.1136/bmj. 15577)

Global determinants of mortality in under $5 \mathrm{~s}: 10$ year worldwide longitudinal study ( $B M J$ 2013; 347: 16427 doi: 10.1136/bmj. 16427) 
Risk of first venous thromboembolism in pregnant women in hospital: population based cohort study from England (BMJ 2013; 347: 16099 doi: 10.1136/ bmj.16099)

Interventions for non-metastatic squamous cell carcinoma of the skin: systematic review and pooled analysis of observational studies (BMJ 2013; 347: 16153 doi: 10.1136/ bmj. 16153)

Effect of reducing total fat intake on body weight: systematic review and meta-analysis of randomised controlled trials and cohort studies (BMJ 2012; 345: e7666 doi: 10.1136/ bmj. e7666)

Effect of $\beta$ blockers on mortality after myocardial infarction in adults with COPD: population based cohort study of UK electronic healthcare records (BMJ 2013; 347: 16650 doi: $10.1136 /$ bmj.16650)

Exploration and confirmation of factors associated with uncomplicated pregnancy in nulliparous women: prospective cohort study (BMJ 2013; 347: 16398 doi: 10.11 bmj.16398)

Hospital readmission performance and patterns of readmission: retrospective cohort study of Medicare admissions (BMJ 2013; 347: 16571/bmj.16571)

Acta Medica Indonesiana (AMI)

Profile and Factors Associated with Mortality in Mediastinal Mass During Hospitalization at Cipto Mangunkusumo Hospital, Jakarta (AMI, Vol. 45, Number 1, January 2013)

Phenotype Characterization of Beta-Lactamase Producing Enterobacteriaceaein the Intensive Care Unit (ICU) of Cipto Mangunkusumo Hospital in 2011 (AMI, Vol. 45, Number 1, January 2013)

Cost-effectiveness of Scaling Up Voluntary Counselling and Testing in West-Java, Indonesia (AMI, Vol. 45, Number 1, January 2013)

Induction of Rat Germ Cell Apoptosis by Testosterone Undecanoate and Depot Medroxyprogesterone Acetate and Correlation of Apoptotic Cells with Sperm Concentration (AMI, Vol. 45, Number 1, January 2013)

The Role of Anti-dengue Virus NS-1 and Anti-protein Disulfide Isomerase Antibodies on Platelet Aggregation in Secondary Dengue Infection (AMI, Vol. 45, Number 1, January 2013)

Distribution of Dimethylarginine-Dimethylamino hydrolase II (DDAH2) Gene Polymorphism in Hemodialysis Patients (AMI, Vol. 45, Number 2, April 2013)

Role of Combined Procalcitonin and Lipopolysaccharide binding Protein as Prognostic Markers of Mortality in Patients with Ventilator-associated Pneumonia (AMI, Vol. 45, Number 2, April 2013)

Detection of Carbapenemase Encoding Genes in Enterobacteriace, Pseudomonas aeruginosa, and Acinetobacter baumaniiIsolated from Patients at Intensive Care Unit Cipto Mangunkusumo Hospital in 2011 (AMI, Vol. 45, Number 2, April 2013)

The Effectiveness of Endoscopic Retrograde Cholangio- pancreatography in the Management of Patients with Jaundice at Cipto Mangunkusumo Hospital, Jakarta (AMI, Vol. 44, Number 4, October 2012)

Predictive Value of Different Estimated Glomerular Filtration Rates on Hospital Adverse Events Following Acute Myocardial Infarction (AMI, Vol. 45, Number 2, April 2013)

The Role of Neutrophyl Lymphocyte Count Ratio as an Inflammatory Marker in Systemic Lupus Erythematosus (AMI, Vol. 45, Number 3, July 2013)

Factors Influencing Bone Mineral Density in ARV-Naïve Patients at Sanglah Hospital, Bali (AMI, Vol. 45, Number 3, July 2013) 
Co-administration of Ritonavir and Primaquine Decreases Plasma Concentration of Primaquine: Single- and Multipledose Study in the Rats (AMI, Vol. 44, Number 4, October 2012)

Transcatheter Closure of Atrial Septal Defects in Adolescents and Adults: Technique and Difficulties (AMI, Vol. 45, Number 3, July 2013)

Safety and Effectiveness of Candesartan and Candesartan/HCT Fixed Dose Combination in Patients with Hypertension (AMI, Vol. 45, Number 3, July 2013)

Do Methicillin Resistant Staphylococcus(MRSA) Carrier Patients Influence MRSA Infection more than MRSA-carrier Medical Officers and MRSA-carrier Family? (AMI, Vol. 45, Number 3, July 2013)

The Role of Xenobotic Metabolism MGST1 Gene Polymorphism in Colorectal Cancer Patients (AMI, Vol. 44, Number 4, October 2012)

Quality of Life People Living with HIV/AIDS: Outpatient in Kramat 128 Hospital Jakarta (AMI, Vol. 44, Number 4, October 2012)

Abdominal Circumference in Relation to Body Weight Gain/Loss in Patients on Chronic Hemodialysis (AMI, Vol. 45, Number 4, October 2013)

Correlation Between T2 Cardiovascular Magnetic Resonance with Left Ventricular Function and Mass in Adolescent and Adult Major Thalassemia Patients with Iron Overload (AMI, Vol. 45, Number 4, October 2013)

Safnil Arsyad is a Professor in English education at the English Department of Education Faculty of Bengkulu University, Indonesia. He has published in several international journals, such as Guidelines, Australian Review of Applied Linguistics, Asia-Pacific Education Researcher, International Journal of Linguistics, Asian ESP Journal, Journal of English as a Foreign Language, Journal of Multicultural Discourses and Asian Englishes. His research interests lie in the area of discourse analysis of academic texts, language teaching and learning material design and English teaching and learning methodology.

Address: Safnil Arsyad, the English Department of Education Faculty of Bengkulu University, Jl. WR. Supratman Kandang Limun Kota Bengkulu, Indonesia. [e-mail: safnilarsyad@gmail.com]

Muhammad Zaim is a Professor in English Language Education at the English Education Department of the Faculty of Languages and Arts of Universitas Negeri Padang in Padang Indonesia. He specializes in English academic discourses and language teaching and materials design and evaluation.

Address: M. Zaim, the English Education Department of Faculty of Languages and Arts of Universitas Negeri Padang, Jl. Prof. Hamka Air Tawar Padang, Sumatera Barat Indonesia. [e-mail: mzaim_unp@yahoo.com] 
Dian Susyla is an Associate Professor in English education at the English Department of Education Faculty of Muhammadyah University of Bengkulu, Indonesia. She specializes in the analysis of academic discourses and language teaching and learning materials evaluation and development.

Address: Dian Susyla, the English Department of Education Faculty of Muhammadyah University of Bengkulu, Jl. Kampung Bali Kota Bengkulu, Indonesia. [e-mail: diansusyla13@yahoo.com] 